\title{
1 Evidence for iceberg fertilization of the NW Atlantic
}

2 Grant R. Bigg ${ }^{1}$, Quentin Jutard ${ }^{2}$, Robert Marsh ${ }^{3}$

$3{ }^{1}$ Department of Geography, University of Sheffield, Sheffield S10 2TN, U. K.

$4{ }^{2}$ ENSTA ParisTech, 1024, Boulevard des Maréchaux, 91762 Palaiseau Cedex, France ; present address: Observatoire

5 Océanologique de Villefranche S/Mer, Sorbonne Université, 4 place Jussieu, 75005 France

$6 \quad{ }^{3}$ School of Ocean and Earth Science, University of Southampton, European Way, Southampton SO14 3ZH, U. K.

Correspondence to: Grant R. Bigg (grant.bigg@sheffield.ac.uk)

Abstract. Icebergs are known to have a significant fertilizing impact on primary productivity in the Southern Ocean, but this link is yet to be investigated in the Northern Hemisphere. This study combines sightings of icebergs with satellite-derived ocean colour data from 1998 to 2015, to seek such a relationship in the NW Atlantic. Despite the obscuring coincidence of the seasonal iceberg flux with the spring bloom of chlorophyll, it is shown that there is a large-scale, one-month-lagged regional correlation between iceberg flux and chlorophyll levels. In addition, a spatial time-lag analysis is consistent with the main cause for the iceberg-chlorophyll relationship being through advection of the nutrients entrained in iceberg meltwater. This leads to a delayed fertilization response of 2-4 weeks. There are a range of possible sources for the nutrients likely leading to this delayed response. The Northern Hemisphere impact of iceberg meltwater on primary production is much less pronounced than in the Southern Ocean, but it is discernible.

\section{Introduction}

Icebergs in the Southern Ocean are known to encourage primary production around themselves through a combination of nutrient and trace element (e.g. iron) release in meltwater (Raiswell et al., 2008), as well as enhancing vertical mixing of nutrients through the ascent and entrainment of submarine meltwater plumes (Helly et al., 2011; Smith et al., 2013). Both satellite (Schwarz and Schodlok, 2009; Duprat et al., 2016; Wu and Hou, 2017) and observational (e.g. Smith et al., 2007; Helly et al., 2011; Biddle et al., 2015) studies have demonstrated this iceberg-driven ocean fertilization around Southern Ocean icebergs, with, in some cases, the impact being visible in plumes extending over several hundreds of kilometres from giant icebergs (Duprat et al., 2016). There are very few observations of the actual deep export of carbon arising from this process (Smith et al., 2011), and some controversy over the conversion of production to export in the Southern Ocean (Martin et al., 2013) and the relative contribution of iron from iceberg 
what limited Lagrangian sediment trap observations exist below typical iceberg depth (Smith et al., 2011) suggest Antarctic icebergs may contribute some 10-20\% of the net deep export of carbon across the Southern Ocean (Duprat et al., 2016), and especially in the seasonal sea-ice zone (Wu and Hou, 2017). In the Northern Hemisphere, many icebergs are calved from Greenland, among other sources (Bigg et al., 1997), every year, with most icebergs that survive to exit their calving fjord entering the North Atlantic or adjacent waters. Many of these eventually enter the Labrador Current (Smith et al., 2013). While the giant icebergs, with lengths exceeding 18 $\mathrm{km}$, observed in the Southern Ocean almost never occur in the Northern Hemisphere, in some years well over a thousand icebergs with lengths from $5 \mathrm{~m}$ up to 3-400 $\mathrm{m}$ remain in the Labrador Current as it passes the southern tip of Newfoundland, at $48^{\circ} \mathrm{N}$ (Bigg et al., 2014). However, little is known of their impact on primary production in the North Atlantic. Shulenburger (1983), while observing some evidence of nutrient mixing, found no evidence for enhanced chlorophyll levels around a Greenland iceberg. Nevertheless, animals from higher trophic levels, such as fish (Holmquist, 1958) and seabirds (Joiris, 2018), are found around Greenland icebergs, suggesting there is an enriched ecosystem locally. In contrast to the iron limiting nature of the Southern Ocean, the Labrador Sea only becomes limited in macronutrients (Harrison and Li, 2008) and micronutrients (Arrigo et al., 2017) in the summer. However, the high latitude North Atlantic is seasonally iron-limited in the Irminger and Iceland Basins (Achterberg et al., 2018; Hopwood et al., 2018). The upwelling meltwater plumes from the base of icebergs, which typically penetrate beneath the late spring/summer mixed layer depth (see Yankovsky and Yashayaev (2014) for an example), potentially provide a means of enhancing and prolonging the nutrient and iron levels in the vicinity of the icebergs. Meltwater from the icebergs themselves, however, also provides a potential means of widespread distribution of iron and nutrients from the Greenland ice sheet, because open ocean iceberg delivery bypasses removal processes in fjords (Hopwood et al., 2019), estuaries and coastal regions (in marked contrast to meltwater or riverine fluxes). In this context it is worth noting that bio-available iron is potentially glacially preserved, and increased through utraviolet light reactions within ice with near-surface sediment (Raiswell et al., 2018), and would then survive until release by melting. The iceberg flux in the Labrador Current typically peaks in April (Bigg et al., 2014), coinciding with the onset of the spring phytoplankton bloom (Fig. 1) - a co-occurrence to which we will return later. However, in the spring of the year with the highest observed iceberg numbers crossing the $48^{\circ} \mathrm{N}$ parallel $(2014 ;>1500)$ since the MODIS ocean colour satellite instruments became available in 2003, while there is a suggestion of enhanced production relative to the longterm mean (area average of $0.79 \mathrm{mg} \mathrm{m}^{-3}$ ), low iceberg years (e.g. 2006 with none and 2010 with 1) had similar or higher average spring production (Fig. 1). There is thus a complex relationship between annual spring productivity over the NW Atlantic and environmental variability, of which the iceberg flux is only a part. Other, largely independent, factors which will affect the strength and timing of the spring bloom will be the intensity and depth of the previous winter's ocean mixing, the rate of spring stratification, and the strength and timing of spring snow-fed river runoff through the 

will attempt to control for these other climate factors by exploring more detailed statistical comparisons of both temporal and spatial relationships between iceberg numbers and chlorophyll levels in the NW Atlantic. The aim is thus to address the productivity component of the question raised by Smith et al. (2013): "Do icebergs in the Arctic also exhibit enrichment or alteration processes of the pelagic ecosystem, ultimately leading to enhanced productivity and carbon export?"
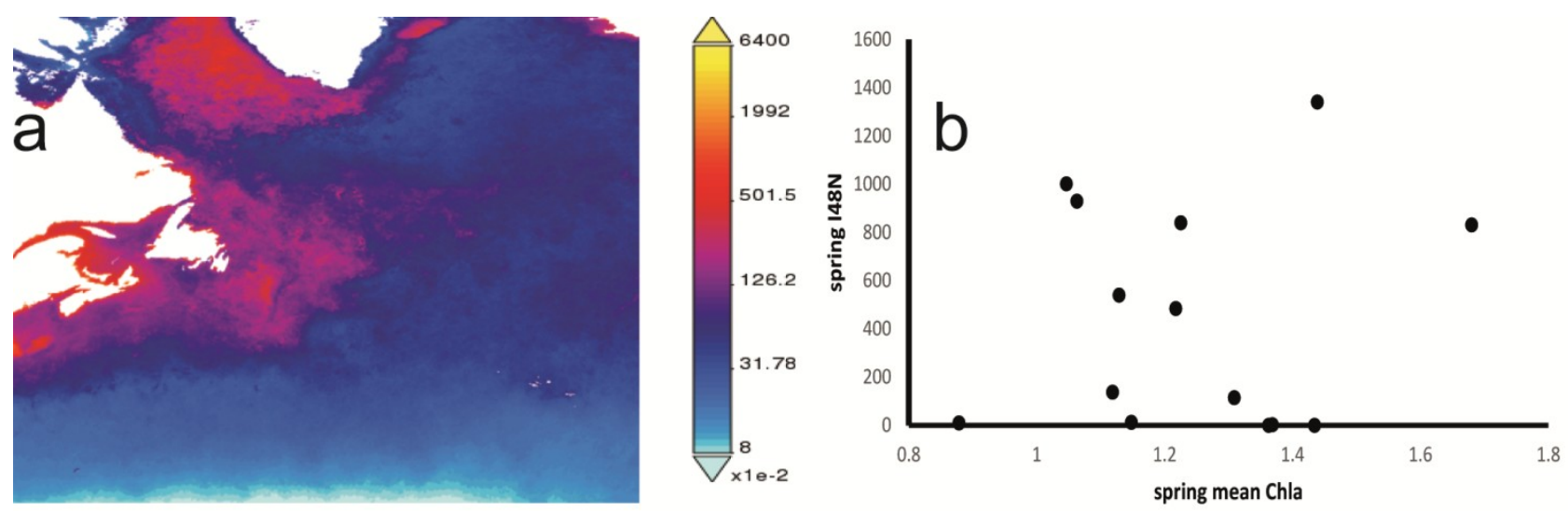

Figure 1: Mean March-May surface chlorophyll levels (in $\mathrm{mg} \mathrm{m}^{-3}$; note logarithmic scale) from the 8-daily $4 \mathrm{~km}$ MODIS ocean colour instrument over the NW Atlantic for 2003-2016: a) spatial pattern of mean, b) scatter plot of spring mean chlorophyll a (chla) vs. spring I48N total. The visualization in a, and the data contributing to b were produced within the GIOVANNI online data system, developed and maintained by the NASA GES DISC.

\section{Data and Methods}

Two main types of data are used in this analysis: iceberg sightings and remotely sensed ocean colour, the latter being a proxy for surface chlorophyll a concentration. There is a record of monthly iceberg numbers crossing the $48^{\circ} \mathrm{N}$ parallel extending back to 1900 (Bigg et al., 2014), and daily iceberg sighting maps back to 2004 for regions south of $52^{\circ} \mathrm{N}$. In addition, a more complete database of iceberg sightings in the Labrador Sea exists from 1960 (IIP, 2016). This does not have all size and shape fields specified for each sighting, varies in format over time, and certainly earlier data has some quality control issues (Wilton et al., 2015). However, the location and timing of all iceberg sightings south of $52^{\circ} \mathrm{N}$ is available for several decades. Ocean colour data is available in a fairly regular form only since the SeaWiFS satellite was launched in 1998, but to obtain a full time series since then requires merging of data from more than one 
https://doi.org/10.5194/os-2021-61

Preprint. Discussion started: 9 August 2021

(C) Author(s) 2021. CC BY 4.0 License.

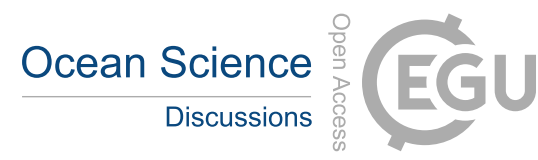

82 instrument, thus requiring calibration. The next section therefore addresses how consistent datasets over our baseline 83 period of 1998-2015 were created from disparate sources. 


\subsection{Data}

\subsubsection{Ocean Colour}

The chlorophyll data were retrieved from https://oceancolor.gsfc.nasa.gov/ for the two satellites SeaWiFS and MODISAqua for the periods 1998-2002 and 2003-2015 respectively. The following $4 \mathrm{~km}$ resolution, Level 3 processed data were collected and averaged over a $1^{\circ} \times 1^{\circ}$ grid: a) monthly averages; b) 8 day averages that included the $15^{\text {th }}$ of each month (not always over the same days of the month) to give a mid-month series; $\mathrm{c}$ ) the 8 day averages that followed those from b); and d) daily averages that were used to calculate 2-7 day averages over the whole year. Note that the mean chlorophyll levels from these two satellites differ, and this difference has some spatial variability (Djavidnia et al., 2010), with the SeaWiFS chlorophyll typically being lower than the MODIS-Aqua values, with a weaker seasonal cycle. It was therefore decided to standardise the entire dataset so that the SeaWiFS and MODIS periods had the same mean and variance, using $S=\bar{M}+\frac{\sigma(M)}{\sigma(S)}(S-\bar{S})$,

where $S$ and $M$ are the time series of SeaWiFS and MODIS data respectively, $\sigma$ is the relevant standard deviation of the whole series and the overbar represents the respective series mean. The impact of this is shown in Supplementary Fig. S1.

\subsubsection{Iceberg data}

Two types of iceberg data were used in this study. As a measure of the overall flux of icebergs in the Labrador Current monthly estimates of the number of icebergs crossing $48^{\circ} \mathrm{N}$ are compiled by the International Ice Patrol (IIP); here we define this as I48N. These data are available from 1900 to 2020 (http://www.navcen.uscg.gov/pdf/iip/International_Ice_Patrols_Iceberg_Counts_1900_to_2011.pdf, supplemented by subsequent annual reports available at https://www.navcen.uscg.gov/?pageName=IIPAnnualReports), although this study only uses the 1998-2015 period for analyses involving I48N, for consistency with the individual sightings database discussed below. A full discussion of the creation and quality of this dataset is given by Christensen and Luzader (2012) and Wilton et al. (2015). It is sufficient here to say that over the time period considered in this research a uniform approach to compiling the monthly count was employed, using a combination of dedicated aircraft surveys, ship reports, short-term iceberg drift modelling and some remote sensing input. Reference to any recent annual report will show the care taken by the IIP in compiling an accurate record, because of the importance of knowing the location of every iceberg threat to safe navigation. 
113 The second type of iceberg data is the location of individual icebergs over the Labrador Sea. The form of this spatiotemporal data varies over time. Over 2009-2015, iceberg positions for the $15^{\text {th }}$ of each month were gridded from the appropriate daily IIP iceberg chart (https:/www.navcen.uscg.gov/?pageName=iipCharts), to a 1 degree precision. To extend the record back to 1998, to coincide with the beginning of the SeaWiFS observation period, we used the IIP iceberg sightings database (IIP, 2016). The observations in this database, which often only contain position and no size information, are predominantly south of $52^{\circ} \mathrm{N}$ so the area over which the iceberg number density was calculated for this study was limited to being south of $52^{\circ} \mathrm{N}$. This region, from $52^{\circ} \mathrm{N}$ to the most southerly iceberg measurement and from the eastern coast of North America out to the most easterly iceberg observation at $35^{\circ} \mathrm{W}$, is defined as the main iceberg area, or as region $A$. However, a technique needed to be designed to reconstruct the monthly map equivalent data from this sightings database over the 1998-2008 period, when iceberg location maps were not available. The period from 2009-2015 was used to test techniques for reconstructing number density fields in region $A$ in the pre2009 period, as the daily charts changed format in 2009, with iceberg numbers becoming numerical rather than being denoted by symbols from that year. The iceberg density reconstruction technique selected used the fact that trajectories of individually identified icebergs in the sightings database could be calculated. This enabled the generation of a Markov chain describing the probability that, after successive days, an iceberg would travel from a given grid square to another. Markov chains of varying temporal lengths can be evaluated, which enabled the determination of the shortest period of prior information required to produce a statistically robust reconstruction for a particular day's iceberg density. The procedure for creating an iceberg density map for the $15^{\text {th }}$ of each month in this way is described in Appendix A. This was the only day's density calculated each month, for compatibility with the 2009-2015 mid-month data set, described above. $I_{\text {sightings }}(x, y)$ is defined as the number of icebergs at the grid point $(x, y)$ as reconstructed from applying the Markov chain.

Measures of the number of icebergs found from the mapping database, $N_{\text {maps }}(x, y, n)$, and the sightings database, $N_{\text {sightings }}(x, y, n)$, respectively are then defined. Here $n$ is the size of area being compared and varies over squares of size $1^{\circ}, 3^{\circ}, 5^{\circ}$ or $7^{\circ}$. Thus

$$
N_{\text {maps }}(x, y, n)=\frac{1}{n^{2}} \sum_{(i, j)=-\frac{n-1}{2}}^{\frac{n-1}{2}} I_{\text {maps }}(x+i, y+j)
$$

and

$N_{\text {sightings }}(x, y, n)=\frac{1}{n^{2}} \sum_{(i, j)=-\frac{n-1}{2}}^{\frac{n-1}{2}} I_{\text {sightings }}(x+i, y+j)$ with $(x, y)$ being (longitude, latitude) of each respective square, $I_{\text {maps }}(x, y)$ being the number of icebergs at the grid point $(x, y)$ on the IIP maps and $I_{\text {sightings }}(x, y)$ deriving from the iceberg sightings database as described above. A measure of the fit of the monthly map reconstruction using the sightings database is the correlation coefficient $C_{n}$, where $C_{n}$ is given by: 
$C_{n}=\frac{\sum_{(x, y) \in A} N_{\text {maps }}(x, y, n) N_{\text {sightings }}(x, y, n)}{\sqrt{\sum_{(x, y) \in A}\left(N_{\text {maps }}(x, y, n)\right)^{2} \sum_{(x, y) \in A}\left(N_{\text {sightings }}(x, y, n)\right)^{2}}}$.

145 The overall correlation of the method to be discussed below can then be expressed in an iceberg number weighted mean, $C_{T, n}$, over the 84 months from January 2009 to December 2015, where

$147 \quad C_{T, n}=\frac{\sum_{m=1}^{84} C_{n}\left(\sum_{(x, y) \in A} I_{m a p s}(x, y, n)\right)}{\sum_{m=1}^{84} \sum_{(x, y) \in A} I_{m a p s}(x, y, n)}$

148 The correlation measure $C_{T, n}$ is shown in Fig. 2. Here the dependence of $C_{T, n}$ on the length of time before the selected day over which the Markov chain is constructed is shown. Even for the finest resolution of 1 degree squares, $C_{T, 1}$ reaches $\sim 0.7$ if 16 or more previous days are used, while for the bigger squares $C_{T, n}$ exceeds 0.95 for those cases. Later analysis in this paper covers the period 1998-2015, where the iceberg density fields for 1998-2008 are reconstructed using a Markov chain extending over 16 days prior to the nominal $15^{\text {th }}$ of each month, and are combined with the midmonth map iceberg density record used for 2009-2015.

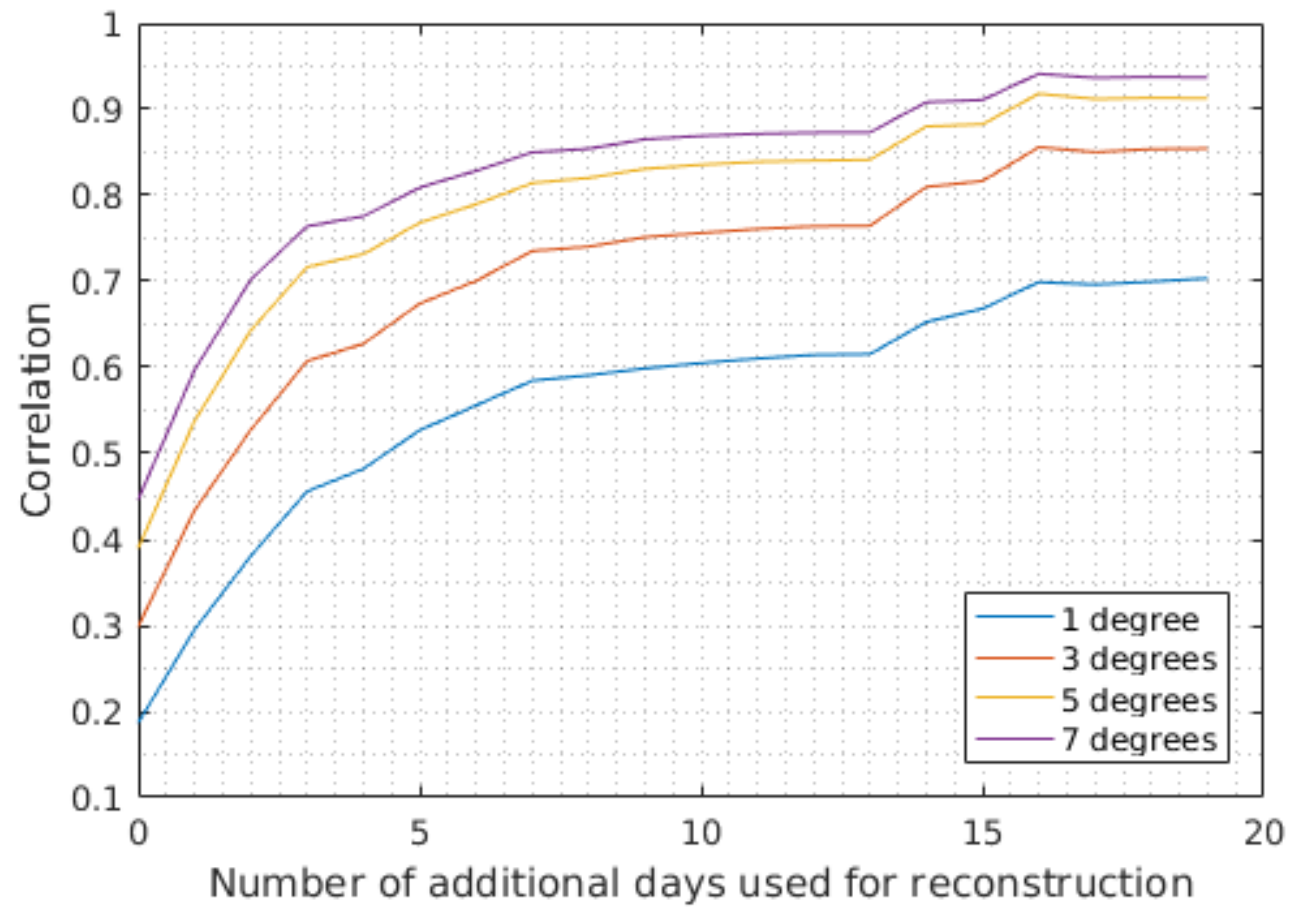

Figure 2: The overall correlation, $C_{T, n}$, for $\mathrm{n}=1,3,5$ and 7 degree squares for reconstructing the observed data over 2009-2015 using the Markov chain approach. 


\subsection{Methods}

159 Seeking an unequivocal link between iceberg fluxes and chlorophyll levels in the Labrador Sea is complicated by the 160 temporal correspondence of the peak iceberg season of spring and early summer with the marine productivity spring 161 bloom (Zhao et al., 2013), in a region close to coasts, with rivers which will have major seasonal variability, including a spring peak flow due to snow melt (Vorosmarty et al., 1998), and considerable benthic sediment resuspension from extensive shallow shelves. The latter can be of similar magnitude to fluxes of iceberg iron (Wadley et al., 2014; Raiswell et al., 2016). Remote sensing analysis in the Southern Ocean also suggests that the impact of fertilization from melting icebergs can have a time lag of some weeks (Schwarz and Schodlock, 2009; Duprat et al., 2016). Two methods, using different mixtures of iceberg and chlorophyll datasets, were employed to try to disentangle any signal from what will be a complex and multiply-forced environment. This task is made even more complicated by the sub-grid scale size of icebergs in the Labrador Sea, relative to ocean colour pixels, compared to the often much larger Southern Ocean icebergs. The two basic methods are described here, with the results of the relevant analyses given in the Results section.

\section{$171 \quad$ 2.2.1 Large-scale comparison}

The first approach to seek a link between iceberg flux and chlorophyll levels uses large-scale comparisons between the IIP's monthly iceberg number crossing $48^{\circ} \mathrm{N}$ (I48N), and a monthly average chlorophyll over the main area of the Labrador Sea through which icebergs drift, or where meltwater entrained in the North Atlantic Drift may be advected over later weeks. A nearby coastal area, which will experience many of the same environmental forcings as the main area, but which almost no icebergs reach, and little iceberg meltwater (see Fig. 13 of Wilton et al., 2015), was also defined as a control area. The main area, or region A, and a control area are shown in Fig. 3. 


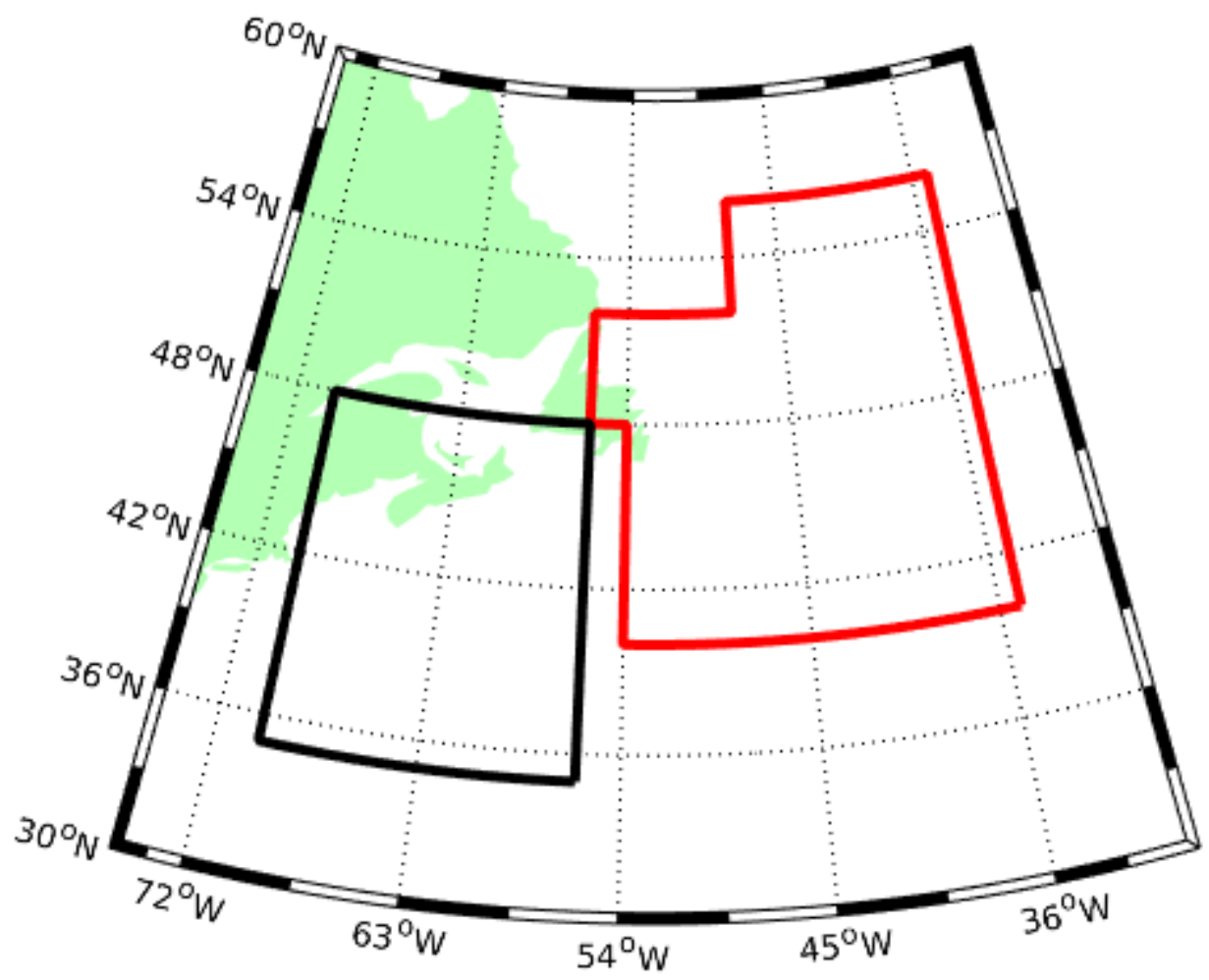

Figure 3: Definition of the main iceberg area (area $\mathrm{A}$, in red) and the control area (black).

To confirm that the control area productivity is indeed experiencing similar environmental forcings to those in the iceberg main area, a series of correlation tests of the MODIS chlorophyll data between the control and iceberg main areas were carried out. Over the almost 18 year period of July 2002 - May 2020 the monthly mean chlorophyll in the control region, at $0.56 \pm 0.22 \mathrm{mg} \mathrm{m}^{-3}$, is indistinguishable from that in the iceberg area $\left(0.69 \pm 0.19 \mathrm{mg} \mathrm{m}^{-3}\right)$, with a statistically significant correlation (at better than the 1\% level) of 0.47 . Note that this correlation increases to 0.61 if the impact of icebergs is minimized by correlating only months from the 5 years with less than 100 icebergs in total passing $48^{\circ} \mathrm{N}$. That icebergs have an impact on the chlorophyll is seen by correlating the monthly mean chlorophyll between the control and iceberg areas for just the months during the peak iceberg season of April-June. Including all years leads to a statistically insignificant correlation of 0.12 , while comparing this spring bloom period for years with less than 100 icebergs raises the correlation to 0.52 , which is statistically significant at the $5 \%$ level. Thus, using chlorophyll in the control area as a means to control for the wider non-iceberg environmental factors affecting regional chlorophyll levels is a valid approach. 
To do this, Pearson correlations were first calculated between the anomalies of the two parameters I48N and chlorophyll (averaged over each of the control and main areas), relative to their monthly averages over the period 19982015. These were calculated over a range of lags from -2 months to 2 months, where a lag $>0$ means I $48 \mathrm{~N}$ leads the chlorophyll. In addition, in order to attempt to correct for changes purely due to non-iceberg effects, partial correlations (Stuart et al., 2008) using the monthly anomalies from the control area as a control parameter, were also carried out using the Matlab function partialcorr (https://uk.mathworks.com/help/stats/partialcorr.html). This approach, of using partial correlation analysis to control for common variation in processes unrelated to the main question being investigated, has been successfully employed in a number of environmental fields, with recent examples in untangling rain:aerosol relationships in marine remote sensing studies (Yang et al., 2016), whether carbon isotope fractionation in phytoplankton is a proxy for $\mathrm{pH}$ (Wang et al., 2016) and the role of salmon species' density-dependence in growth (Morita and Fukuwaka, 2020). The idea behind partial correlation is to minimize the impact of forcing processes common to both variables (or regions in this case) on the resulting correlation. While partial correlation remains not the same as causation, a significant partial correlation increases confidence that there may be a plausible link between the two correlating variables.

\subsubsection{Local temporal comparison}

A more local approach was to carry out a temporally lagged correlation the total of the mid-monthly icebergs recorded over the main area (Fig. 3), $I_{T}$, obtained from the spatial distribution constructed as described above in section 2.1.2, with the time-lagged local chlorophyll across much of the North Atlantic $\left(36-66^{\circ} \mathrm{N}, 75-30^{\circ} \mathrm{W}\right)$. It is worth noting that $I_{T}$ is used as the measure of iceberg number, rather than a spatial field, as the geographical distribution of icebergs is very variable in both space and time and makes a completely local correlation problematic in all regions except near the coast. In such areas the correlation is mostly statistically significant, but it is difficult to separate a direct iceberg effect from the influence of other local environmental factors affecting chlorophyll levels. A large-scale measure of iceberg number is therefore retained, but one with a contribution of much more spatial information than the IIP's I48N employed in the last section. The correlation was carried out over the full iceberg season (February to August; Bigg et al. (2014)). As with the largescale comparison method described in the last section, the data used were monthly anomalies. To minimize the impact of natural variability in the chlorophyll field linked directly or indirectly across the whole North Atlantic to variability in the weather a control parameter was also used here to produce a partial correlation. This control parameter needed to have a more extensive spatial and physical remit than the control area chlorophyll used in the last section, while still being largely independent of the iceberg measure, $I_{T}$. After a range of tests, the control parameter was chosen to be the North Atlantic Oscillation (NAO), using the NAO Index of Hurrell and Deser (2009; https://climatedataguide.ucar.edu/climate-data/hurrell-north-atlantic-oscillation-nao-index-pc-based). The NAO is a 
large scale measure of the tropospheric circulation over the North Atlantic, strongly linked to Arctic atmospheric circulation as well as being highly correlated with a range of climatic factors across the northern Atlantic (Hurrell and Deser, 2009; Reintges et al., 2017). However, previous work has shown that the NAO is not linearly correlated with the Greenland Ice Sheet mass balance (Hanna et al., 2011), which is one of the main variables indirectly responsible for the Greenland iceberg flux (Zhao et al., 2016). There is a weak, non-linear, link between significantly lagged (> 6 months) NAO and I48N (Zhao et al., 2016), nevertheless, the recent NAO Index can be used as a control parameter as it affects current and recent climate, but not iceberg flux. The control parameter uses the NAO lagged by 3 months compared to the month of examination, as this lag had the most impact on reducing the natural variability component of the chlorophyll. Note that the use of partial correlation analysis as a way to remove the impact of specific climate signals from a process study is common, with recent examples in untangling rainfall/cyclone:sea temperature relationships (He et al., 2016; Hong et al., 2018; Srinivas et al., 2018), and the impact of the lower stratosphere on tropical cyclone intensity (Ferrara et al., 2017). As Southern Ocean analyses have shown that the time lag between iceberg melting and ocean fertilization is likely to be days to weeks (Schwartz and Schodlok, 2009; Duprat et al., 2016), the daily chlorophyll data at each point across the North Atlantic were converted into a series of 5 day average fields. The measures $I_{T}$ and the NAO Index, were then linearly interpolated between their monthly values to provide analogous 5-day series over 1998-2015, 5 day averages being chosen to reduce the impact of cloud cover on chlorophyll observations. Restricting the analysis to the peak iceberg months of February-August, and using a control parameter of the 3-month lagged NAO Index, $I_{T}$ and the chlorophyll field were then partially correlated over a set of 5 day interval lags from 0 days to 70 days, with $I_{T}$ leading. This gives a measure of how any relationship between iceberg number and chlorophyll not dependent on the NAO spatially evolves over time across the NW Atlantic; the results of this analysis are shown below.

\section{$248 \quad$ 3.1 Large-scale comparison}

Fig. 4 shows the Pearson correlations between monthly anomalies of I48N and the monthly mean chlorophyll over both the main area and the control region (Fig. 3), over the period 1998-2015. The methodology was described in section 2.2.1 above. Correlations with lags up to \pm 2 months are shown, as well as partial correlations, controlling for the chlorophyll levels in the control area. It is expected that correlations should be positive if there is any causal link and, sensibly, only lags $\geq 0$ months show any positive correlations. However, the only correlations of any sign statistically significant at the 0.05 level (correlations $>|0.131|, 212$ degrees of freedom) are those with a 1 month lag. Here, the correlation of I48N with the main area chlorophyll is significant, and this is also true in the partial correlation case, when controlled for the chlorophyll natural variability of the control area. 


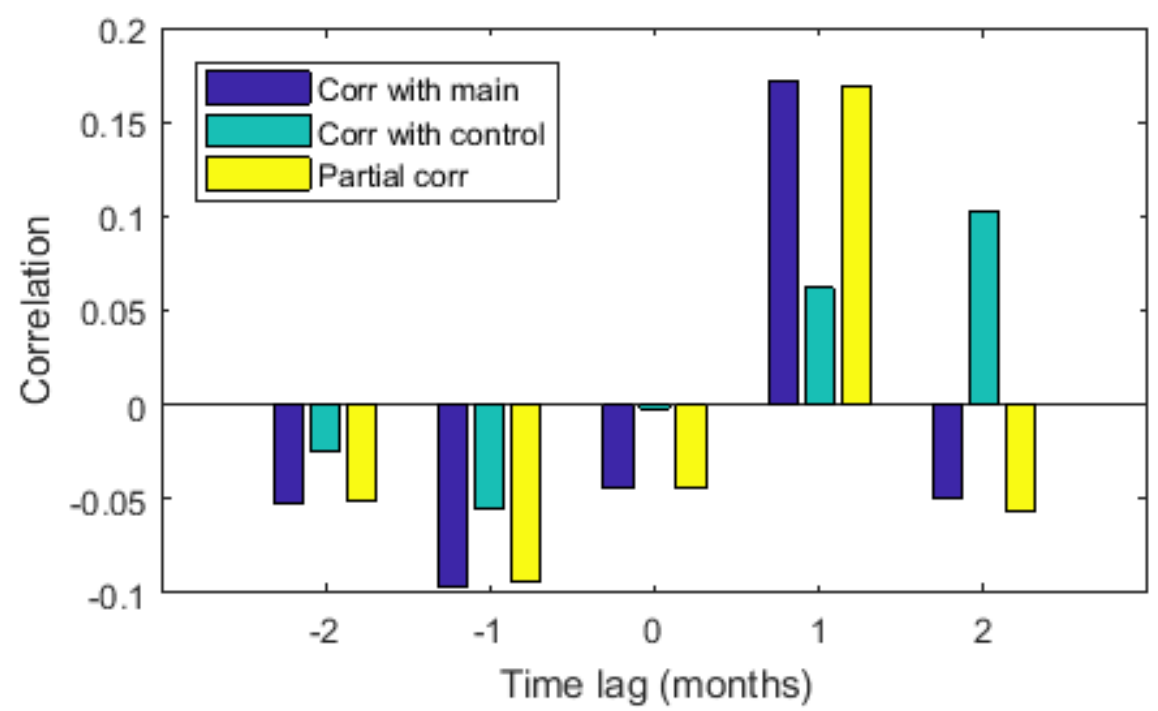

Time lag (months)

Figure 4: Lagged Pearson correlations between monthly chlorophyll anomalies in both main and control areas and I48N, over 1998-2015. Only the +1 month correlation and partial correlation on the main area are

This result is consistent with there being a large-scale link between increasing iceberg numbers and fertilization of the ocean a month later. It is suggestive rather than definitive, however, as the correlations are low in magnitude and the increasing correlation of I48N with chlorophyll within the control area, with greater lag, is consistent with there being a strong spring bloom amplification occurring after the peak iceberg flux of April/May. This result cannot shed light on the question of the potential reality or cause of such a link, if real, whether it is restricted to the immediate vicinity of the melting icebergs, extends to the mixing downstream of the iceberg meltwater with the ocean, or is a mixture of both local and remote effects. In the next section we will explore this question further.

\subsection{Local temporally evolving comparison}

Fig. 5a shows a spatial view of the instantaneous correlation of monthly main area iceberg total number, $I_{T}$, with local monthly mean chlorophyll, with the significant squares shown in Fig. 5b. This shows a region of zero-lag positive correlation off Newfoundland, in the control region and where iceberg density is greatest (Fig. S2), but also other patches of statistically significant positive and negative correlation elsewhere across the NW Atlantic (Fig. 5b). However, many of these significant correlation patches, particularly south of $48^{\circ} \mathrm{N}$, are linked to the variation in the weather, as reflected in the NAO state 3 months previously (see Figs. $5 \mathrm{c}$ and d). 


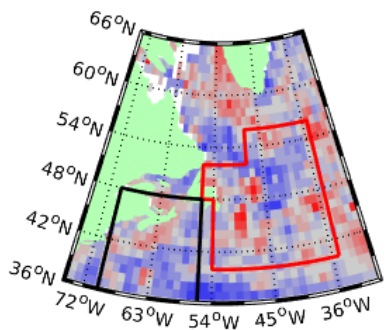

a) Correlation of local $\mathrm{chl}$ with the total number of icebergs on the main area

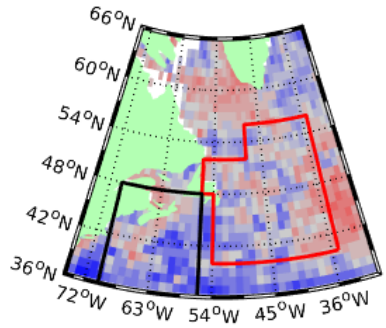

c) Correlation of local chl with the NAO index ( 3 months earlier)

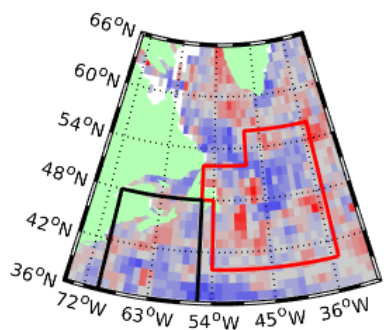

e) Partial correlation of chl with icebergs, using NAO as control

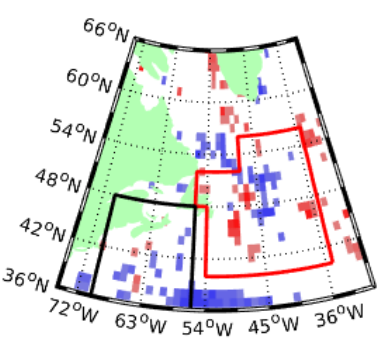

b) Same map with a $0.05 \mathrm{p}$-value sill

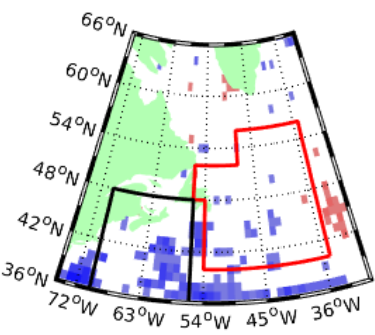

d) Same map with a 0.05 p-value sill

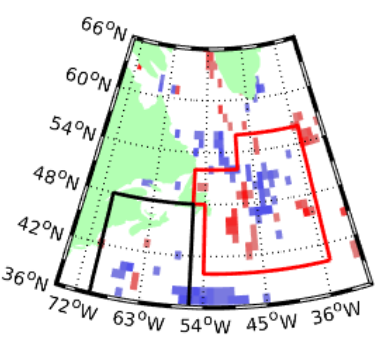

f) Same map with a $0.05 \mathrm{p}$-value sill

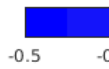

Figure 5: Correlation between local chlorophyll anomalies and 1) $I_{T}$, a) raw correlation; b) areas statistically significant at 0.05 level; 2) the NAO Index from 3 months earlier, c) raw correlation; d) areas statistically significant at 0.05 level; and 3) partial correlation with $I_{T}$, controlled by the NAO Index lagged by 3 months, e) raw correlation; f) areas statistically significant at 0.05 level. The main iceberg, and control, areas are shown in red and black respectively, as also shown in Figure 3.

The partial correlation, controlled for weather variability through use of the 3-month lagged NAO Index, is therefore shown in Figs. 5e and 5f. The latter shows that many of the more southerly statistically significant regions seen in Fig. 5 b disappear under this control, however, the signal in the main area, off Newfoundland remains, as do areas off Greenland. These areas of statistically positive correlation that remain, however, tend to be somewhat fragmented and there are also some significant negative correlations in an arc from the Labrador coast into the central North Atlantic. 
288 Nevertheless, note the lack of any coherent area of statistically significant partial correlation within the control region. 289 These equivocal signals are consistent with the limited direct correlation between I48N and chlorophyll shown in Fig. 4.

290 That analysis suggested that it required a month before the full impact of fertilization by the melting icebergs became 291 visible. The analysis is therefore extended to consider this lag component in more detail.

292 Using the technique outlined in Sect. 2.2.2, a series of partial correlations over 1998-2015 between 5 day series of $I_{T}$ 293 and chlorophyll were carried out over a range of lags from 0 days to 70 days. A sub-set of the correlations showing 294 those squares with a statistical significant partial correlation at the 0.05 level is shown in Fig. 6. An animation of this 295 full correlation map sequence is available in the Supplementary Material. Note that the region over which correlations 296 are possible varies with the lag combination due to the persistent presence of cloud cover in the northern Atlantic restricting the number of cloud-free pixels, particularly for the larger dataset of shorter lag.

298 This series of lagged partial correlations shows an interesting evolution, with a distinct zero lag positive correlation in 299 the vicinity of the main iceberg stream in the Labrador Current (that is, the main area of Fig. 3), changing towards a more general, if lower, correlation over the NW Atlantic by a lag of 10 days, which then strengthens into a more homogeneous region of positive correlation south of Greenland by day 20, peaking by day 30 . This begins to decay after day 30 and has essentially disappeared by day 50 . There are initially some regions of relatively strong positive correlation in the central east Atlantic and negative correlation in the control region and the Sargasso Sea, but these decay fairly quickly. They are probably remnants of environmental chlorophyll impacts not due to the iceberg flux, but not totally removed by the NAO control. A possible cause could be a light- and stratification-related spring bloom signal (Behrenfeld and Boss, 2014) occurring during the peak iceberg months of April and May (Bigg et al., 2014). It is also worth noting that the high chlorophyll correlation adjacent to the Greenland coast in Fig. 6 may be partially due to local icebergs (not monitored by the IIP) or meltwater from Greenland glaciers (Arrigo et al., 2017). However these local icebergs are closely confined to coastal waters (see charts at https://www.dmi.dk/en/groenland/hav/ice-charts/), and the impact of local fjord meltwater is limited to periods after the I48N iceberg peak has decreased (early July onwards) and restricted to the Greenland shelf region of the Labrador Sea (Arrigo et al., 2017). The majority of the correlation signal south of $57^{\circ} \mathrm{N}$ is therefore likely due to the relationship with I48N rather than Greenland meltwater. 

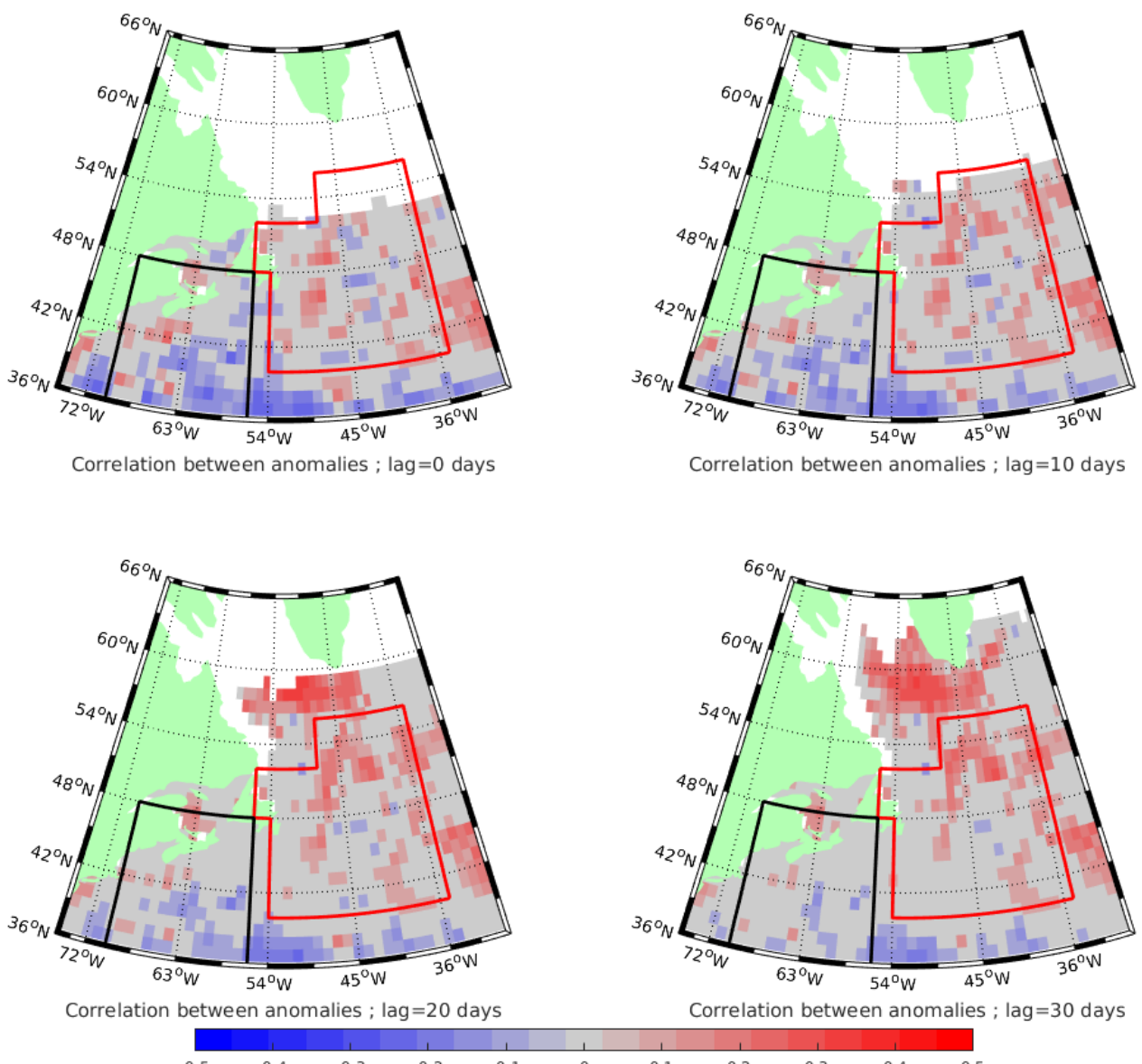

Correlation between anomalies; lag=30 days

Figure 6: Partial correlation of $I_{T}$ and chlorophyll at 4 different lags: a) 0 days; b) 10 days; c) 20 days; d) 30 days. outside $[-0.5,0.5]$ are set to the colour bar limit. The main iceberg, and control, areas are shown in red and black respectively, as also shown in Figure 3.

\section{Discussion}

The approaches tested here for examining whether there is a measure of correlation between iceberg number density and chlorophyll in the NW Atlantic all agree that one exists over the region, with the signal stronger with a lag of several weeks to a month between a change in iceberg numbers and a response in the chlorophyll field. The NW Atlantic, however, has distinctly different background conditions to the Southern Ocean, where both the size of the 
icebergs and the high nutrient-low chlorophyll nature of the region allows clear and pronounced plumes of production to be visibly associated with icebergs (Schwarz and Schodlok, 2009; Duprat et al., 2016; Wu and Hou, 2017). In the NW Atlantic the peak of the natural light-driven spring bloom, enhanced by the inputs from land and coastal waters, as well as the presence of a pronounced nutrient source through winter mixing (Fragoso et al., 2016), coincides with the natural release of icebergs into the Labrador Current after being locked in winter sea-ice further north (Marko et al., 1994). Thus, while a correlation between icebergs and chlorophyll is discernible in Figs. 4-6, the use of partial correlations, with a control for chlorophyll in a control area (Fig. 4), and inter-annual and monthly climate variability through the NAO (Figs. 5-6), was required to make the signal more robust.

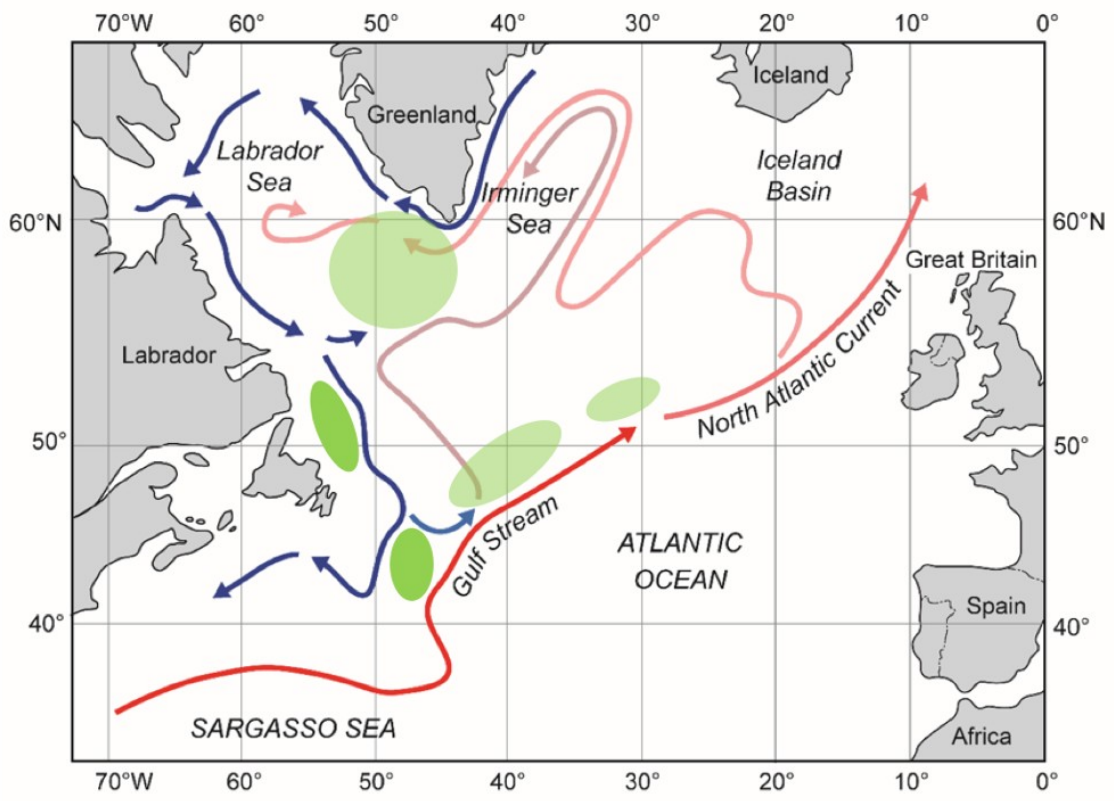

Figure 7: A schematic of the surface circulation in the North Atlantic, derived from the satellite observations of Ohashi et al. (2013). The colours are indicative of sea surface temperatures in the currents shown, varying from cold (blue) to warm (red). The background shading schematically indicates proposed regions of iceberg fertilization at lags of 0 (bright green) to 1 month (pale green), where the zero lagged fertilization is likely to be due to the direct impact of the icebergs melting, while the delayed response is due to the impact of meltwater advection. See text for more details. Note that the boundary of the Labrador Sea is taken to be the line extending from the eastern tip of Newfoundland to the southern tip of Greenland. 
The lag of roughly a month between iceberg number increase and chlorophyll response, seen in Figs. 4 and 6, shows that an indirect fertilization effect, following dispersing iceberg meltwater, is the most likely source for the delay. Figs. 5 and 6 both suggest an immediate, zero lag, impact of iceberg melting, but confined to the "Iceberg Alley" off the coast of Newfoundland. However, Fig. 6 shows that the stronger lag relationship at 1 month seen in the main area comparison of Fig. 4 is largely due to correlation in areas further east and north than the Labrador Current itself. This is consistent with the iceberg meltwater and entrained nutrients from individual iceberg melting plumes (Smith et al., 2013), with the resulting dispersion of accompanying fertilizing nutrients and trace elements from both types of sources, being entrained into the North Atlantic Current and mixed into the Labrador Sea further east and north. A schematic of this circulation and the associated iceberg fertilization is shown in Fig. 7. With a typical surface North Atlantic Drift circulation, with a magnitude of $\sim 0.5 \mathrm{~ms}^{-1}$ (Ohashi et al., 2013), in a month there is sufficient time for the dispersing meltwater to travel $\sim 1000 \mathrm{~km}$, into the east of the Labrador Sea and the main North Atlantic Ocean, potentially leading to the northward and eastward advective pattern shown in Fig. 6 and the Supplementary video. Note that the time delay between melting and observed chlorophyll enhancement may be due to a number of causes and so difficult to confirm without further modelling or observations. These causes, however, include i) direct effect of the meltwater dispersion, ii) biologically-, chemically- or photoelectrically- induced delay in the conversion of iron from a colloidal to a bioavailable form (Shaked and Lis, 2012; Raiswell et al., 2018), or iii) a time delay caused by the response of phyotoplankton to the unevenly enriched environment. Thus, the regional upper ocean circulation is consistent with the fertilization mechanism postulated by Smith et al. (2013) for Greenland icebergs, and could underlie the partial correlation analyses shown here. Unfortunately, there are no recorded direct observations of NW Atlantic individual icebergs showing clear fertilizing evidence. The NW Atlantic, particularly in the spring, is a nutrient-rich area (Zhao et al., 2013; Saba et al., 2015). However, the region, away from the vicinity of Greenland (Arrigo et al., 2017), is potentially subject to iron limitation (Rijkenberg et al., 2014; Achterberg et al., 2018). While it cannot be definitively shown from observations at this time, it is possible that the chlorophyll enhancement associated with higher iceberg density in the NW Atlantic is partially driven by the dissolved iron supply (Raiswell et al., 2016; Raiswell et al., 2018) from the melting icebergs. Nevertheless, it is possible to produce a first order estimate of the likely flux of iron delivered by icebergs to the NW

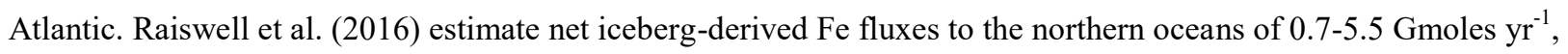
more than an order of magnitude greater than their estimated Fe atmospheric dust flux to the Arctic. While $\sim 80 \%$ of the former's iceberg Fe will be transported in icebergs calving from Greenland (Bigg et al., 1997), most such icebergs will melt, either entirely or in large part, before they enter the Labrador Current. Marsh et al. (2018) estimated that only $2.5 \%$ of the calved iceberg flux reaches the red box of the main area in Fig. 3. There is considerable calving variability from year to year, resulting in wide variations in iceberg flux entering our core area from one year to the next (Bigg et 

leads to a mean iceberg flux of $13.1 \mathrm{~km}^{3} \mathrm{yr}^{-1}$ entering our study area. This flux mostly melts over approximately the three month period of April to June (Wilton et al., 2015). Using our above figures leads to a mean Fe flux to our core area of 0.0047-0.0367 Gmoles/month. While icebergs are intrinsically isolated objects slowly melting over time during their ocean passage, if we make the leading order approximation that the melt is spread roughly evenly over the $2.75 \times 10^{12} \mathrm{~m}^{2}$ of our core area, and noting 1 mole $\mathrm{Fe} \sim 0.056 \mathrm{~kg}$, leads to a net iceberg-derived Fe flux to the core Labrador Sea over the spring peak melt season of $9.57 \times 10^{-8}-7.47 \times 10^{-7} \mathrm{kgm}^{-2} / \mathrm{month}$ or $0.32-2.49 \times 10^{-8} \mathrm{kgm}^{-2} \mathrm{~d}^{-1}$. This is a tiny Fe flux, subject to a wide range of uncertainty from a range of factors linked to the nature of icebergs calved from Greenland, their survivability, and their passage through the Labrador Sea. However, it needs to be compared to typical Fe fluxes to the surface Labrador Sea from other sources. Achterberg et al. (2018) estimated upper ocean Fe fluxes in the sub-polar Atlantic from vertical upwelling to be much smaller than aerial fluxes, meaning this component of Fe flux can be neglected. Shelley et al. (2017) measured dry and wet deposition aerial Fe fluxes from the atmosphere to the ocean in spring 2014, the year of the greatest iceberg flux in the Labrador Current this century. They found similar wet and dry deposition fluxes over the Labrador Sea of $1-2 \mu \mathrm{gm}^{-2} \mathrm{~d}^{-1}$, so giving a maximum of $4 \mu \mathrm{gm}^{-2} \mathrm{~d}^{-1}$, or $0.4 \times 10^{-8} \mathrm{kgm}^{-2} \mathrm{~d}^{-1}$, of aerial Fe deposition. This value is similar to that at the minimum end of the above estimated iceberg-delivered Fe flux during a normal year, let alone a year with roughly double the mean iceberg flux. This suggests that in many years the iceberg-derived flux is likely to be a major Fe delivery mechanism to the Labrador Sea.

\section{Conclusion}

The analysis presented in this paper has shown that, if care is taken to minimize the impact of seasonal and weatherrelated forcings, there is a weak but statistically significant correlation between iceberg number density and chlorophyll concentrations approximately a month later in the NW Atlantic. This relationship is not so strongly spatially linked as in the Southern Ocean (e.g. Duprat et al., 2016), and is found within an environment whose productivity is naturally highly variable, even in the absence of icebergs (Fig. 1). However, the relationship was found in different approaches to analysis of a mix of data sets. It is suggested that there is a physico-ecological relationship linked to the advection of iceberg meltwater, both direct and from the impact of upwelling of basal meltwater plumes, and the nutrients and trace elements the melt plume contains, leading to a small-scale local impact where icebergs are found off Newfoundland, but a larger, delayed, impact downstream in the portion of the North Atlantic Drift entrained into the eastern Labrador Sea. Smith et al. (2013) speculated that this iceberg effect was likely to exist in the North Atlantic and here we have moved towards confirming its presence. The analysis has also shown that it is possible that it is iceberg-delivered Fe that contributes to this enhanced productivity. In the Southern Ocean the impact of icebergs, and giant icebergs in particular, on the storage of carbon in the deep ocean has been shown to be significant (Duprat et al., 2016). In the Northern 
Hemisphere the difficulty of isolating the iceberg signal means this impact on the global carbon cycle is likely to be much less here. However, the suggested enhancement of productivity by icebergs in the highly productive region of the NW Atlantic means that this effect would be worth quantifying.

Code and data availability. Algorithms are available as Supplementary Material. All observational data used in this study are available as described in section 2 Data.

Author contributions. QJ performed the analyses. GRB drafted the manuscript and led the project. RM contributed some of the iceberg data and helped with the interpretation of the analysis. All authors contributed equally to the manuscript

Acknowledgements. We would like to thank ENSTA Paristech for giving QJ the opportunity to take a research internship at the University of Sheffield during the summer preceding the fourth year of his Engineering degree (2017), when the bulk of the research reported here was carried out. We are grateful to the US Coast Guard for compiling and archiving IIP iceberg observations and charts, and to NASA for archiving the ocean colour datasets used here. Tom Lees and Jacob Marsh assisted with digitization of the 2009-2015 IIP iceberg charts.

\section{APPENDIX A RECONSTRUCTING ICEBERG DENSITY USING MARKOV CHAINS}

The approach taken consists of running two algorithms, firstly one that builds the probability distribution of an iceberg moving from one square to another in one day from a Markov chain, which is then used by a second algorithm that constructs the iceberg density.

The first algorithm (Supplementary Algorithm 1) records every time an iceberg crosses from one grid square to another in the form of a matrix, Crossings. In order to properly reflect the speeds of the icebergs the method also needs to record all the times when the iceberg stayed in the same grid square - this corresponds to the diagonal of the matrix. So, for example, if two sightings in two different squares are separated by $\mathrm{N}$ days, the algorithm assumes it spent one day crossing the line and half of the remaining time $((\mathrm{N}-1) / 2)$ in each of the squares. Note that if between two sightings the iceberg stayed in the same grid square, the algorithm counts $\mathrm{N}$ days as stationary. The final matrix of probabilities is a normalized version of Crossings. There will be empty rows; these are rows that were never visited by icebergs. They are completed by placing a 1 in the diagonal for mathematical convenience; this will have no impact on the simulations. The second algorithm (Supplementary Algorithm 2) is the one that applies the Markov chain method. It only needs to use the last known position of an iceberg before the $15^{\text {th }}$ of the month and simulates its drifting for the remaining days. 
https://doi.org/10.5194/os-2021-61

Preprint. Discussion started: 9 August 2021

(c) Author(s) 2021. CC BY 4.0 License.

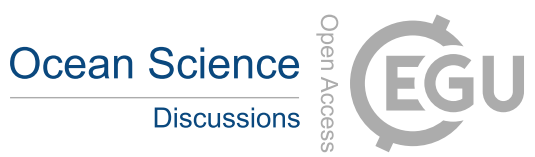

(c) (1)

439 multiplies this by the matrix of probabilities generated by Algorithm 1 to obtain the probabilities of presence for the 440 next day. This needs to be repeated for every remaining day until the 15 th, which is equivalent to taking the matrix to 441 the power of the number of remaining days. Note that if the last sighting happens exactly on the 15th, then that power is 442 zero and the matrix reduces to the identity matrix, which will correctly record one iceberg at the right position. The 443 main caveat of this method is that it assumes that the probability of an iceberg crossing from one square to another is 444 independent of the time it spent in the former square. However, the procedure gave satisfactory results even with this 445 approximation. 


\section{References}

Achterberg, E. P., Steigenberger, S., Marsay, C. M., LeMoigne, F. A. C., Painter, S. C., Baker, A. R., Connelly, D. P., Moore, C. M. et al. (2018) Iron biogeochemistry in the high latitude North Atlantic Ocean. Sci. Rep., 8, doi: 10.1038/s41598-018-19472-1.

Arrigo, K. R., van Dijken, G. L., Castelao, R. M., Luo, H., Rennermalm, Å. K., Tedesco, M., Mote, T. L., Oliver, H., and Yager, P. L. (2017) Melting glaciers stimulate large summer phytoplankton blooms in southwest Greenland waters, Geophy. Res. Lett., 44, 6278-6285, 2017.

Bamber, J., van den Broecke, M., Ettema, J., Lenaerts, J., and Rignot, E. (2012) Recent large increases in freshwater fluxes from Greenland into the North Atlantic. Geophys. Res. Lett., 39, L19501.

Behrenfeld, M. J., and Boss, E. S. (2014). Resurrecting the ecological underpinnings of ocean plankton blooms. Ann. Rev. Mar. Sci., 6, 167-194.

Bhatia, M. P., Kujawinski E. B., Das S. B., Breier, C. F., Henderson, P. B., and Charette, M. A. (2013) Greenland meltwater as a significant and potentially bioavailable source of iron to the ocean. Nature Geosci., 6, 274-278.

Biddle, L. C., Kaiser, J., Heywood, K. J., Thompson, A. F., and Jenkins, A. (2015) Ocean glider observations of icebergenhanced biological production in the northwestern Weddell Sea. Geophys. Res. Lett., 42, 459-465.

Bigg, G. R., Wadley, M. R., Stevens, D. P., and Johnson, J. A. (1997) Modelling the dynamics and thermodynamics of icebergs. Cold Regions Sci. Technol., 26, 113-135.

Bigg, G. R., Wei, H., Wilton, D. J., Zhao, Y., Billings, S. A., Hanna, E., and Kadirkamanathan, V. (2014) A century of variation in the dependence of Greenland iceberg calving on ice sheet surface mass balance and regional climate change. Proc. Roy. Soc. Ser. A, 470, 20130662, doi:10.1098/rspa.2013.0662.

Christensen, E., and Luzader, J. (2012) From sea to air to space: a century of iceberg tracking technology. Coast Guard Proc. Mar. Safety Security Council, 69, 17-22.

Djavidnia, S., Melin, F., and Hoepffner, N. (2010) Comparison of global ocean colour data records. Ocean Sci., 6, 61-76.

Duprat, L. P. A. M., Bigg, G. R., and Wilton, D. J. (2016) Enhanced Southern Ocean marine productivity due to fertilization by giant icebergs. Nature Geosci., 9, 219-221.

Ferrara, M., Groff, F., Keshavamurthy, K., Robeson, S. M., and Kieu, C. (2017) Large-scale control of the lower stratosphere on variability of tropical cyclone intensity. Geophys. Res. Lett., 44, 4313-4323.

Fragoso, G. M., Poulton, A. J., Yashayaev, I., Head, E. J. H., Stinchcombe, M. C., Purdie, D. A. (2016) Biogeographical patterns and environmental controls of phytoplankton communities from contrasting hydrographic zones of the Labrador Sea. Prog. Oceanogr., 141, 212-226. 
https://doi.org/10.5194/os-2021-61

Preprint. Discussion started: 9 August 2021

(c) Author(s) 2021. CC BY 4.0 License.

Hanna, E., Huybrechts, P., Cappelen, J., Steffen, K., Bales, R. C., Burgess, E., McConnell, J., Steffensen, J. P., Van den Broeke, M., Wake, L., Bigg, G. R., Griffiths, M., and Savas, D.: Greenland Ice Sheet surface mass balance 1870 to 2010 based on Twentieth Century Reanalysis, and links with global climate forcing, J. Geophys. Res. Atmos., 116, D24121, doi:10.1029/2011JD016387, 2011.

Hawkings, J. R., Wadham, J. L., Tranter, M., Raiswell, R., Benning, L. G., Statham, P. J., Tedstone, A., Nienow, P. et al. (2014) Ice sheets as a significant source of highly reactive nanoparticulate iron to the oceans. Nat. Commun., 5, doi: 10.1038/ncomms4929.

Harrison, W. G., and Li, W. K. W. (2008) Phytoplankton growth and regulation in the Labrador Sea: light and nutrient limitation. J. Northwest Atl. Fish. Sci., 39, 71-82.

He, Z., Wu, R., and Wang, W. (2016) Signals of the South China Sea summer rainfall variability in the Indian Ocean. Clim. Dyn., 46, 3181-3195.

Helly, J. J., Kaufmann, R. S., Stephenson, G. R., and Vernet, M. (2011) Cooling, dilution and mixing of ocean water by freedrifting icebergs in the Weddell Sea. Deep-Sea Res. II, 58, 1336-1345.

Hendry, K. R., Huvenne, V. A. I., Robinson, L. F., Annett, A., Badger, M., Jacobel, A. W., Ng, H. C., Opher, J. et al. (2019) The biogeochemical impact of glacial meltwater from southwest Greenland. Prog. Oceanogr., 176, doi:10.1016/j.pocean.2019.102126.

Holmquist, C. (1958) An observation on young specimens of Ammodytes dubius. Meddelelser Grønl., 159, 1-14.

Hong, C.-C., Lee, M.-Y., Hsu, H.-H., and Tseng, W.-L. (2018) Distinct influences of the ENSO-like and PMM-like SS anomalies on the mean TC genesis location in the western North Pacific: the 2015 summer as an extreme example. $J$. Clim., 31, 3049-3059.

Hopwood, M. J., Bacon, S., Arendt, K., Connelly, D. P. and Statham, P. J. (2015) Glacial meltwater from Greenland is not likely to be an important source of Fe to the North Atlantic. Biogeochem., 124, 1-11.

Hopwood, M. J., Carroll, D., Browning, T. J., Meire, L., Mortensen, J., Krisch, S., and Achterberg, E. P.: Non-linear response of summer-time marine productivity to increased meltwater discharge around Greenland, Nature Comm., 9 , https://doi.org/10.1038/s41467-018-05488-08, 2018.

Hopwood, M. J., Carroll, D., Höffer, J., Achterberg, E. P., Meire, L., Le Moigne, F. A. C., Bach, L. T., Eich, C., Sutherland, D. A., and González, H. E.: Highly variable iron content modulates iceberg-ocean fertilisation and potential carbon export, Nature Comm., 10, 5261, https://doi.org/10.1038/s41467-019-13231-0, 2019.

Hurrell, J. W, and Deser, C. (2009) North Atlantic climate variability: The role of the North Atlantic Oscillation. J. Mar. Sys., 78, 28-41.

International Ice Patrol (1995), updated 2016. International Ice Patrol (IIP) Iceberg Sightings Database, Version 1. Boulder, Colorado USA. NSIDC: National Snow and Ice Data Center. doi: http://dx.doi.org/10.7265/N56Q1V5R. [Date Accessed: 4 January 2018]. 
https://doi.org/10.5194/os-2021-61

Preprint. Discussion started: 9 August 2021

Joiris, C. R. (2018) Hotspots of kittiwakes Rissa tridactyla tridactyla on icebergs off southwest Greenland in autumn. Pol. Biol., 11, 2375-2378.

Lancelot, C., de Montety, A., Goosse, H., Becquevort, S., Schoemann, V., Pasquer, B., and Vancoppenolle, M. (2009) Spatial distribution of the iron supply to phytoplankton in the Southern Ocean: a model study. Biogeosci., 6, 2861-2878.

Marko, S. R., Fissel, D. B., Wadhams, P., Kelly, P. M., and Brown, R. D. (1994) Iceberg severity off eastern North America - its relationship to sea-ice variability and climate-change. J. Clim., 7, 1335-1351.

Marsh, R., Bigg, G. R., Zhao, Y., Martin, M. J., Blundell, J. R., Josey, S. A., Hanna, E., and Ivchenko, V. (2018) Prospects for seasonal forecasting of iceberg distributions in the North Atlantic. Nat. Hazards, 91, 447-471.

Martin, P., van der Loeff, M. R., Cassar, N., Vandromme, P., d'Ovidio, F., Stemmann, L., Rengarajan. R., Soares, M. et al. (2013) Iron fertilization enhanced net community production but not downward particle flux during the Southern Ocean iron fertilization experiment, LOHAFEX. Glob. Biogeochem. Cyc., 27, 871-881.

Morita, K., and Fukuwaka, M. (2020) Intra- and interspecific density-dependent growth and maturation of Pacific salmon in the Bering Sea. Ecol. Res., 35, 106-112.

Ohashi, K., Han, G., Chen, N., and Helbig, J. (2013) Northwest Atlantic surface circulation from multi-satellite observations. J. Atmos.-Ocean, 51, 35-49.

Perner, K., Moros, M., Otterå, O. H., Blanz, T., Schneider, R. R., and Jansen, E. (2019) An oceanic perspective on Greenland's recent freshwater discharge since 1850. Sci. Rep., 9, doi:10.1038/s41598-019-53723-z.

Raiswell, R. Benning, L. G., Tranter, M., and Tulaczyk, S. (2008) Bioavailable iron in the Southern Ocean: the significance of the iceberg conveyor belt. Geochem. Trans., 9, doi: 10.1186/1467-4866-9-7.

Raiswell, R., Hawkings, J. R., Benning, L. G., Baker, A. R., Death, R., Albani, S., Mahowald, N., Krom, M. D. et al. (2016) Potential bioavailable iron delivery by iceberg-hosted sediments and atmospheric dust to the polar oceans. Biogeosci., 13, 3887-3900.

Raiswell, R., Hawkings, J., Elsenousy, A., Death, R., Tranter, M., and Wadham, J. (2018) Iron in glacial systems: speciation, reactivity, freezing behaviour, and alteration during transport. Front. Earth Sci., 6, 222, doi:10.3389/feart.2018.00222.

Reintges, A., Latif, M., and Park, W.: Sub-decadal North Atlantic Oscillation variability in observations and the Kiel climate model, Clim. Dyn., 48, 3475-3487, doi: 10.1007/s00382-016-3279-0, 2017.

Rijkenberg, M. J. A., Middag, R., Laan, P., Gerringa, L. J. A., van Aken, H. M., Schoemann, V., de Jong, J. T. M., and de Baar, H. J. W. (2014) The distribution of dissolved iron in the west Atlantic Ocean. PLOS One, 9, doi:10.1371/journal.pone.0101323.

Saba, V. S., Hyde, K. J. W., and Rebuck, N. D. (2015) Physical associations to spring phytoplankton biomass interannual variability in the US Northeast Continental Shelf. J. Geophys. Res. Biogeosci., 120, 205-220.

Schwarz, J. N., and Schodlok, M. P. (2009) Impact of drifting icebergs on surface phytoplankton biomass in the Southern Ocean: ocean colour remote sensing and in situ iceberg tracking. Deep-Sea Res. I, 56, 1727-1741. 
https://doi.org/10.5194/os-2021-61

Preprint. Discussion started: 9 August 2021

Shaked, Y., and Lis, H. (2012) Disassembling iron availability to phytoplankton. Fron. Microbiol., 3, doi:10.3389/fmicb.2012.00123.

Shaw, T. J., Raiswell, R., Hexel, C. R., Vu, H. P., Moore, W. S., Dudgeon, R., and Smith Jr., K. L. (2011) Input, composition and potential impact of terrigenous material from free-drifting icebergs. Deep-Sea Res. II, 58, 1376-83.

Shelley, R. U., Roca-Martí, M., Castrillejo, M., Sanial, V., Masqué, P., Landing, W. M., van Beek, P., Planquette, H., et al. (2017) Quantification of trace element atmospheric deposition fluxes to the Atlantic Ocean ( $>40^{\circ} \mathrm{N}$; GEOVIDE, GEOTRACES GA01) during spring 2014. Deep-Sea Res. I, 119, 34-49.

Shulenberger, E. (1983) Water-column studies near a melting Arctic iceberg. Polar Biol., 2, 149-158.

Smith Jr., K. L., Robison, B. H., Helly, J. J., Kaufmann, R. S., Ruhl, H. A., Shaw, T. J., Twining, B. S., and Verrnet, M. (2007) Free-drifting icebergs: hot spots of chemical and biological enrichment in the Weddell Sea. Science, 317, 478-82.

Smith Jr., K. L., Sherman, A. D., Shaw, T. J., Murray, A. E., Vernet, M., and Cefarelli, A. O. (2011) Carbon export associated with free-drifting icebergs in the Southern Ocean. Deep-Sea Res. II, 58, 1485-1496.

Smith Jr., K. L., Sherman, A. D., Shaw, T. J., and Sprintall, J. (2013) Icebergs as unique Lagrangian ecosystems in polar seas. Ann. Rev. Mar. Sci., 5, 269-287.

Srinivas, G., Chowdary, J. S., Kosaka, Y., Gnanaseelan, C., Parekh, A., and Prasad, K. V. S. R. (2018) Influence of the Pacific-Japan Pattern on Indian Summer Monsoon rainfall. J. Clim., 1, 3943-3958.

Statham, P. J., Skidmore, M., and Tranter, M. (2008) Inputs of glacially derived dissolved and colloidal iron to the coastal ocean and implications for primary productivity. Glob. Biogeochem. Cyc. 22, doi: 10.1029/2007GB003106.

Stuart, A., Ord, J. K., and Arnold, S. (2008) Kendall's Advanced Theory of Statistics, Volume 2A, Classical Inference and the Linear Model, $6^{\text {th }}$ ed., Wiley, Chichester.

Vorosmarty, C. J., Fekete, B. M., and Tucker, B. A. (1998) Global river discharge, 1807-1991, V1.1 (RivDIS). Dataset. Available online [http://www.daac.ornl.gov] from Oak Ridge National Laboratory Distributed Active Archive Center, Oak Ridge, Tennessee, U.S.A.

Wadley, M. R., Jickells, T. D., and Heywood, K. J. (2014) The role of iron sources and transport for Southern Ocean productivity. Deep-Sea Res. I, 87, 82-94.

Wang, S., Yeager, K. M., and Lu, W. (2016) Carbon isotope fractionation in phytoplankton as a potential proxy for pH rather than for $\left[\mathrm{CO}_{2}(\mathrm{aq})\right]$ : observations from a carbonate lake. Limnol. Oceanogr., 61, 1259-1270.

Wilton, D. J., Bigg, G. R., and Hanna, E. (2015) Modelling twentieth century global ocean circulation and iceberg flux at $48^{\circ} \mathrm{N}$ : implications for west Greenland iceberg discharge. Prog. Oceanogr., 138, 194-210.

$\mathrm{Wu}, \mathrm{S}$. Y., and Hou, S. (2017) Impact of icebergs on net primary productivity in the Southern Ocean. Cryosphere, 11, 707722.

Yang, Y., Russell, L. M., Lou, S., Liu, Y., Singh, B., and Ghan, S. J. (2016) Rain-aerosol relationships influenced by wind speed. Geophys. Res. Lett., 43, 2267-2274. 
https://doi.org/10.5194/os-2021-61

Preprint. Discussion started: 9 August 2021

(C) Author(s) 2021. CC BY 4.0 License.

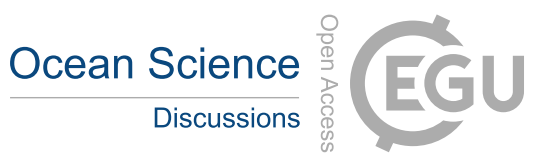

Yankovsky, A. E., and Yashayaev, I. (2014) Surface buoyant plumes from melting icebergs in the Labrador Sea. Deep-Sea Res. I, 91, 1-9.

Zhao, H., Han G., and Wang, D. (2013) Timing and magnitude of spring bloom and effects of physical environments over the Grand Banks of Newfoundland. J. Geophys. Res. Biogeosci., 118, 1385-1396.

580 Zhao, Y., Bigg, G. R., Billings, S. A., Hanna, E., Sole, A. J., Wei, H., Kadirkamanathan, V., and Wilton, D. J.: Inferring the variation of climatic and glaciological contributions to West Greenland iceberg discharge in the Twentieth Century, Cold Reg. Sci. Technol., 121, 167-178, doi:10.1016/j.coldregions.2015.08.006, 2016. 